\title{
Human Dimensions Approach towards Integrating Sustainable Transportation and Urban Planning Policies: A Decision Support System (DSS) Based on Stated Preferences Data
}

\author{
Wolfgang Rid1,2 \\ ${ }^{1}$ Institute of Urban Planning and Design, University of Stuttgart, Stuttgart, Germany \\ ${ }^{2}$ Urban and Regional Economics, Erfurt University of Applied Sciences, Erfurt, Germany \\ Email: wolfgang.rid@fh-erfurt.de
}

How to cite this paper: Rid, W. (2017) Human Dimensions Approach towards Integrating Sustainable Transportation and Urban Planning Policies: A Decision Support System (DSS) Based on Stated Preferences Data. Theoretical Economics Letters, 7, 814833.

https://doi.org/10.4236/tel.2017.74059

Received: March 1, 2017

Accepted: June 11, 2017

Published: June 14, 2017

Copyright $\odot 2017$ by author and Scientific Research Publishing Inc. This work is licensed under the Creative Commons Attribution International License (CC BY 4.0).

http://creativecommons.org/licenses/by/4.0/

\begin{abstract}
While a lot of progress has been made in Germany to reduce $\mathrm{CO}_{2}$ emissions in the past years in almost all sectors of economy, however, the sector of transportation shows increasing $\mathrm{CO}_{2}$ emissions in the same period of time. Likewise, sustainability objectives of German land use policies have not been met so far, especially with regard of the continuously high rate of greenfield land used up for new housing development. In this paper, it is argued that environmental issues of both sectors have to be addressed by integrating urban housing development and transportation infrastructure planning policies. The paper reports on a stated preferences survey among house buyers in Germany, using a discrete choice approach, where parameters of sustainable urban design and sustainable transport are both integrated into one model. Building on concepts of behavioral economics, preferences are elicited for sub-samples of different "environmental awareness". Results show differences in tastes for higher building densities to reduce land consumption as well as differences in tastes for transport infrastructure development and frequency of public transport parameters. In addition, a decision support system is developed to analyze the impact of individual parameters on choosing one alternative over the other. Form this, conclusions on potential market shares for sustainable housing and transport development are drawn and recommendations are given to implement integrated urban design and transportation infrastructure policies.
\end{abstract}

\section{Keywords}

Integrated Land Use and Transportation Planning, Discrete Choice Modelling, Decision Support System (DSS), 


\section{Introduction}

Urban and transportation planning can be considered as the result of both administrative and functional logics of land use [1]. On one side, governmental administrations regulate land use by means of rather informal and general principles of spatial planning or binding land use policies. On the other side, land use functions determine demand for e.g. transportation needs or residential and urban development on behalf of the residents of urban areas. Urban and transportation planning, therefore, is concerned with balancing policy objectives with the needs and the demand of people living in the specific urban or regional area.

One of the main objectives of land use policies in Germany is to reduce $\mathrm{CO}_{2}$ emissions and land use consumption. Today, Germany reports on a total of 902 Mio. $\mathrm{t}$ of $\mathrm{CO}_{2}$ emissions per year [2]. While there has been some progress and a decline in $\mathrm{CO}_{2}$ emissions of $4.6 \%$ is reported for the period of 2009 to 2014, however, the sector of transportation shows increasing $\mathrm{CO}_{2}$ emissions in the same period of time. Turning to the sector of housing development, environmental problems also concern the amount of Greenfield land being used up for new housing development and transport infrastructure. While the German government has targeted a limit of 30 ha of greenfield land used up for new housing development and transport infrastructure per day, this number was as high as 73 ha/day in 2015 [3]. This is mainly attributed to the dominant lifestyle model in housing development in Germany, where studies suggest that almost $80 \%$ of all young Germans aspire to a life in a single family home or duplex/semi-detached houses with own gardens and associated low building densities [4]. The demand for single-family homes has even been growing recently, which means growing demand for new building sites ([5], p. 144). Moreover, typical site developments in Germany usually are characterized by providing car-oriented infrastructure, i.e. streets and car parking to improve access of buildings by means of individual transport. This adds to using up even more greenfield land with regard to housing development. To sum it up, there is a need to address both environmental issues of high $\mathrm{CO}_{2}$ emissions and high rate of greenfield land used up for housing development and transportation infrastructure.

Consequently, among other things, the German government tries to address two main fields of action in its "Federal Sustainability Strategy", (1) a sustainable housing development and (2) a sustainable transportation sector, respectively [6]. With regard to housing development, the German government has for example established different forms of subsidies to support energy-efficient residential buildings. Likewise, in the transportation sector, the German government has funded numerous research programs and pilot projects to support innovative forms of transport, such as car- and bike-sharing systems or new vehicle technologies such as electric vehicles. 
In this paper, we use the concept of "sustainable housing development" to integrate the objectives of the urban planning and transportation sector. In Germany, concepts of "sustainable housing development" have been frequently discussed in policy and academic literature from the early 1980s on, as guidelines to reduce the negative environmental effects of new housing developments. "Ecological" and "sustainable" housing development concepts are being discussed as useful planning guidelines to reduce the negative environmental effects of housing developments. "Ecological housing" focuses on the reduction of the negative ecological impact of new housing development, for instance by employing innovative construction techniques such as thermal insulation, solar energy use or heat exchanging systems [7]. "Sustainable housing", in contrast, additionally addresses social and economic issues, building upon the concept of sustainability [8]. According to sustainability objectives, resource consumption should not exceed a specified maximum level in order to preserve enough resources to allow future generations to consume at similar levels [7] [9]. Sustainable housing concepts, for example, suggest higher building densities to save land resources or promote sustainable means of individual transport such as mixed-use developments to reduce travel demand or cluster parking and connected walkways to the houses [7] [10].

The market share of "sustainable" housing development in Germany, however, is still very low [7] and estimated to be well below $10 \%$ of the total of newly constructed residential buildings in Germany [11]. In 2015, private households are building $65 \%$ of the total of newly constructed residential buildings [12]. Consequently, Sieverts (2005) described the pattern of housing developments as a result of innumerable individual decisions, primarily made by private households [13].

The group of private home buyers, therefore, can be seen as important stakeholders in housing development ultimately deciding whether housing development will include aspects of sustainability or not with their investment decisions. Hence, the study presented here will discuss sustainable housing development from a demand-side perspective and using a behaviour-oriented investigative approach, which has the target group of private home buyers at its centre.

To do so, the study presented here will use data from a stated preference survey among households who are intending to buy residential real estate in the near future in Germany. In this paper, the individual decisions made by private households will be modelled using inferential statistics from the empirical survey. This was done to analyze potential demand for sustainable housing development planning scenarios, which included for example higher building density scenarios as well as scenarios of sustainable transport in order to analyze potential market shares for housing development alternatives that reduce land consumption and $\mathrm{CO}_{2}$ emissions. In addition, a decision support system (DSS) will be presented that allows a more detailed discussion of the results with regard to specific scenarios of sustainable housing and transport planning.

This article is organized in five sections. First, the article outlines the characteristics of choice and discusses background theory of behavioral economics, 
followed by a short overview of the method of the discrete choice experiment. Next, the study design is presented and the latent class model is introduced as analysis model. In Section 4, the results are given for the preferences analysis, followed by an in-depth discussion of results using a decision support system (DSS). Section 5 concludes on policy recommendations towards integrated land use-und transportation planning policies.

\section{Theoretical Background of Mode Choice: From Rational Choice to Bounded Rationality and the Discrete Choice Experiment}

\subsection{Mode Choice Research: Rational Choice \& Bounded Rationality}

When people make decisions, e.g. whether to invest into sustainable housing or choose sustainable transportation services, it is usually assumed that the principles of their choices are based on the paradigm of maximizing a well-ordered utility-function. As a neoclassical conception of human beings, the so-called homo economicus has a full capacity of unrestricted rationality and chooses a course of action in line with a multi-dimensional utility function that includes all information available and centres a clearly defined goal to maximize a desired outcome. However, empirical evidence demonstrates that this model produces numerous anomalies and is in many cases oversimplifying. In contrast to this axiomatic foundation of behaviour, empirical observations in social and behavioural sciences show that human decision-making significantly differs from these assumptions. Human decision-making underlies constraints such as limited time, limited knowledge, limited resources and limited cognitive capacities [14]. Also, decisions may become interfered by specific "belief systems", such as "environmental awareness". Accordingly, Simon establishes the concept of bounded rationality as counter-concept to the "fully" rational homo economicus: According to Simon, behaviour is not only determined by some consistent overall goal and a calculus of expectation but is rather a function or interplay of both mind and environment. Hence, bounded rationality means to study the "cognitive processes (including emotions) that people actually rely on to make decisions" (47: 534), e.g. their ability or inability to evoke knowledge when it is relevant, to work out the consequences of their actions, to conjure up possible courses of action, to cope with uncertainty (...), and to adjudicate among their many competing wants [15].

The concept of bounded rationality, therefore, deals with the cognitive or other limitations of human beings that determine the decisional process (Table 1). Simon furthermore challenges the paradigm of maximising the behavioural outcomes by defining the satisficing-paradigm. This paradigm implies that the process of decision-making is determined by an aspiration level as target variable that a behavioural alternative has to fulfil. For instance, people may indeed opt for a more expensive alternative, because it was the first acceptable option presented to them. 
Table 1. Exemplary contrast of utility-maximising and bounded rational behavior.

\begin{tabular}{|c|c|c|}
\hline Utility-maximising rationality & vs. & Bounded rationality \\
\hline Axiomisation of utility and subjective probability [16] [17]: & & $\begin{array}{l}\text { Taking account of the choice context and } \\
\text { behavioural process [15] [18] [19] [20] [21]: }\end{array}$ \\
\hline $\begin{array}{l}\text { - Paradigm of "fully" rational decision \& maximizing } \\
\text { utility or profit-function } \\
\text { - } \text { Axioms of rationality are based on market transparency and total } \\
\text { information on behavioral alternatives, relevant attributes and } \\
\text { related consequences as well as definite and transitive preferences } \\
\text { - No cognitive limitations in processing attributes } \\
\text { and choice alternatives }\end{array}$ & & $\begin{array}{l}\text { - Satisficing instead of optimizing criteria } \\
\text { - Individuals do not base choices on time-consistent } \\
\text { utility functions over all objects } \\
\text { - Individuals have partial, imperfect biased cognitive } \\
\text { representations and use decisional heuristics to cope } \\
\text { with choice under uncertainty } \\
\text { - "Framing" decisional context influences the } \\
\text { estimation of behavioural consequences }\end{array}$ \\
\hline
\end{tabular}

Moreover, environmental support is a key factor to induce behavioural changes. The amount and quality of transport options that are available to dwellers as well as the practicability of car use in a community limits or encourages mode choices. However, sustainable transport services and sustainable housing options are depending on individual investment decisions made by private homebuyers. In this paper, it is argued that homebuyers investment decisions are "bounded", e.g. by preconceptions such as "environmental awareness" of respondents.

Therefore, in this piece of research, we intend to analyse preferences for sustainable housing and transport planning scenarios against the background of the "environmental awareness" of respondents. To do so, we added items to the questionnaire to be able to segment respondents of "low" or "high environmental awareness", respectively.

\subsection{The Discrete Choice Experiment}

A quantitative procedure which is especially suitable to analyze the research target as described above is the discrete choice analysis, which builds on a conditional logit model and whose roots lie in quantitative psychology. The discrete choice experiment (DCE) method has the advantage of accounting for the multi-attribute nature, which characterizes most behavioral decision-making processes. In addition, choice set alternatives may include currently non-existing alternatives and provide insights into the trade-off behavior of respondents [22]. The procedure is primarily characterized by its ability to consider dependent variables with qualitative scale features, also called discrete variables, in a logistical regression model. A concrete example of this are the purchasing or choice decisions where the consumer chooses a particular alternative (e.g., sustainable housing variant) from a particular number of alternatives (evoked set, e.g., conventional vs. sustainable housing variants), showing differing characteristics (e.g., high or low building densities). In discrete choice analysis, a statistical design plan controls the composition of the alternatives and the choice-sets, e.g. following an orthogonal factorial design [23] [24].

For the analysis of DCE data, several statistical procedures are available to 
model consumers trade-off decisions; however, these procedures differ with respect to accounting for heterogeneities of tastes. Most commonly, the multinomial logit model (MNL) is applied in order to estimate respondents preferences based on DCE data [22]. The MNL, however, assumes homogeneous preferences across respondents [25]. In contrast, the DCE literature indicates the value of the random parameter logit model (RPL), which explicitly accounts for heterogeneity by allowing model parameters, i.e. the attributes of housing development alternatives, to vary randomly over individuals. While the RPL does account for heterogeneity, it is less well suited to explain the sources of heterogeneity [26]. In this study, therefore, we applied a latent class model to analyze the DCE data (see Section 3.2).

\section{Study Design}

\subsection{Survey and Data Collection}

To analyze preferences for sustainable housing concepts, we included eight variables to the empirical model (see Table 2).

The first four attributes of the model, i.e. "building density", "quality of green spaces", "infrastructure provision" and "central plaza", pertain to the neigh-

Table 2. Empirical model of "sustainable housing development": attributes and attribute levels.

\begin{tabular}{|c|c|c|}
\hline & Attributes & Attribute characteristics \\
\hline (1) & Building density & $\begin{array}{l}\text { 1. Low (approx. } 80 \% \mathrm{EFH} ; 20 \% \mathrm{DH} \text { ) } \\
\text { 2. Medium (approx. } 40 \% \mathrm{RH} \text { and } \mathrm{DH} ; 40 \% \mathrm{EFH} \text { ) } \\
\text { 3. High (approx. } 80 \% \mathrm{RH} \text { and } \mathrm{DH} ; 10 \% \mathrm{GW} \text { ) }\end{array}$ \\
\hline (2) & Number of green spaces & $\begin{array}{l}\text { 1. Small number (few green areas; approx. } 1 \mathrm{~GB} / 1 \mathrm{~KB} \text { on every second site) }{ }^{* *} \\
\text { 2. Medium number (some green areas; approx. } 1 \mathrm{~GB} / 1 \mathrm{~KB} \text { per site) } \\
\text { 3. High number (large green areas; approx. } 1 \mathrm{~GB} / 1 \mathrm{~KB} \text { per site and two streets } \\
\text { additionally lined with trees) }{ }^{* *}\end{array}$ \\
\hline (3) & Central plaza & $\begin{array}{l}\text { 1. No central plaza } \\
\text { 2. Central plaza provided } \\
\text { 3. Central plaza and nearby shopping facilities provided }\end{array}$ \\
\hline (4) & Infrastructure provision & $\begin{array}{l}\text { 1. Auto-oriented (streets for cars and car parking directly at the buildings) } \\
\text { 2. Pedestrian-oriented (cluster parking and walkways to the buildings) }\end{array}$ \\
\hline (5) & Public transportation & $\begin{array}{l}\text { 1. Low transit service frequency (1- } 2 \text { services/day) } \\
\text { 2. Medium transit service frequency ( } 3-6 \text { services/day) } \\
\text { 3. High transit service frequency }(7-9 \text { services/day) }\end{array}$ \\
\hline (6) & $\begin{array}{l}\text { Technical installations for resource } \\
\text { protection (e.g. solar panels) }\end{array}$ & $\begin{array}{l}\text { 1. No technical installations for resource protection provided } \\
\text { 2. Technical installations provided (e.g. solar panels) }\end{array}$ \\
\hline (7) & Representation of social classes & $\begin{array}{l}\text { 1. No social mixing (social structure of residents is homogeneous, } \\
\text { e.g. with regard to income and age) } \\
\text { 2. Mixed social structure (social structure of residents is heterogeneous, } \\
\text { e.g. with regard to income and age) }\end{array}$ \\
\hline (8) & $\begin{array}{l}\text { Costs } \\
\text { (The costs are represented } \\
\text { as relative values compared } \\
\text { to the other alternatives) }\end{array}$ & $\begin{array}{l}\text { 1. Same building costs } \\
\text { 2. } 10 \% \text { higher building costs (housing development } \\
\text { A costs } 10 \% \text { more than housing development B) } \\
\text { 3. } 10 \% \text { lower building costs (housing development } \\
\text { A costs } 10 \% \text { less than housing development B) }\end{array}$ \\
\hline
\end{tabular}

Key: ${ }^{\star} \mathrm{GW}=$ apartments; $\mathrm{RH}=$ row house; $\mathrm{DH}=$ duplex/semi-detached house; $\mathrm{EFH}=$ single family home. ${ }^{* *} \mathrm{~GB}=$ Large tree; $\mathrm{KB}=$ small tree. 
borhood layout. The "low" building density level was calculated to equal 0.2 GFZ (German technical expression of gross floor area), the "medium" level to equal $0.4 \mathrm{GFZ}$ and the "high" level to equal 0,6 GFZ. The different levels of green spaces were designed using different levels of quantity of trees planted on each site or along two of the main roads, respectively (see Table 2 for details).

The neighborhood layout was also allowed to show two different types of transport infrastructure, (1) auto-oriented road design, i.e. streets for cars and car parking provided directly at the buildings (2) pedestrian-oriented design, i.e. cluster parking and walkways to the buildings. The neighborhood design was extended to allow for the comparison of housing profiles with (1) no central plaza (2) a central plaza built up on site and (3) a central plaza provided with additional nearby shopping facilities.

The first four attributes were depicted as 3D-CAD visualization for ease of comprehension of differences in neighborhood layout. Four additional housing development characteristics were presented as additional textual information to the housing profiles and were allowed to vary on two or three levels, respectively (see Table 2). "Frequency of local public transportation" pertained to the quality of local transportation service provided at the housing development site and took on three different levels, i.e. "low-" (1 - 2 services/day), "medium-" (3 - 6 services/day) or "high-frequency of transit" (7 - 9 service/day). Also, the housing profiles varied in terms of whether or not "technical installations for resource protection (solar panels)" are provided on site, or whether the social structure of residents was heterogeneous with regard to income and age or not. Also, a "cost" attribute was provided as a generic attribute, which was specified as such as it could either account for (1) same building costs, (housing profile A costs the same than housing profile B), (2) housing profile A costs $10 \%$ less than housing development B and (3) housing profile A costs $10 \%$ more than housing profile B. The cost attribute was specified to measure relative cost differences rather than absolute cost measures in terms of $\$$ or Euros, as we intended to account for cost constraints in the house buying decision of households but did not intend to measure Willingness-To-Pay for each attribute.

The method of collecting information was an internet-based questionnaire that took on the format of descrete choice. Each respondent was presented with four different "choice sets". One choice set consisted of two housing development profiles and a "none"-option, which was provided for respondents who felt that neither of the two housing development options was acceptable to them. The respondents were asked to choose the most preferred alternative in each choice set. A statistical experimental design plan was developed to control the composition of the housing profiles and the choice sets following a fractoral and orthogonal factorial design. This is necessary to calculate regression parameters in compliance with the assumptions of regression theory [23]. In this study, 36 alternatives, each consisting of eight attributes with two or three attribute levels, were required to build 18 choice sets to carry out the discrete choice experiment (for attributes and attribute levels see Table 2). Each of the respondents was 
presented with only four choice-sets, as literature shows that a higher number of choice tasks might "lead to fatigue of the respondents and unreliability of their answers" [27]. The four choice-sets presented to each respondent were drawn by random from the database of the total of 18 choice-sets.

The average age of home buyers in Germany is about 40 years [28]. Dutton reports on a high degree of internet use for respondents of this age-cohort, therefore, we assumed an internet survey appropriate to reach the target group of private home buyers [29]. German internet-discussion groups were informally surveyed to identify those discussion groups, where private home buyers share information and/or experience. The web administrators of five internet discussion groups were asked to forward an email that contained the web-link to the internet survey, which was hosted on the universitys web-server. In addition, two of the biggest southern German housing developers were asked to forward the email invitation to the target group of private home buyers, using their databases on clients email listings.

The survey database recorded 732 entries, 312 of which were incomplete and 420 complete. The high number of in-complete questionnaires ("survey dropout rate") is not unusual in internet-based surveys [30]. About $85 \%$ of the incomplete surveys were aborted after answering the third page of the questionnaire. From the 420 complete responses, 18 questionnaires had to be deleted from the database to avoid biased data as the recorded time for completion was below five minutes, which was believed to be the minimum time required to answer the questionnaire. Thus, the database was reduced to 402 respondents. All the respondents answered four choice sets, making 1608 responses available for the analysis. Unfortunately, it was not possible to calculate the response rate, as the email invitation to the questionnaire was sent out by the internet discussion group's webmasters, who did not release any detailed information about their web-community, e.g. the exact number of forum members.

\subsection{Latent Class \& Segmentation Analysis ("Environmental Awareness")}

Latent class analysis (LCA) has attracted increasing interest from CE researchers due to its accounting for preference heterogeneity in DCE data. LCA identifies market segments based on the concept of endogenous (latent) preference segmentation. LCA, class or segment membership is probabilistic and assumed to be jointly affected by both respondents "choices and respondents" answers to attitudinal questions, such as data on environmental consciousness [25] [31]. The number of market segments or the relative size of the segments, respectively, can be evaluated by test statistics, such as the BIC or AIC.

The estimations were carried out with Latent Gold Choice 4.0 software. Statistical analysis models used in this software are based on individual-specific choice frequencies and, in this study, on the conditional logit model (CLM). This model

allows estimation of how nominal outcomes are affected by characteristics of the 
outcomes which vary across individuals. In this study, the outcomes are housing alternatives, which are described by several attributes e.g. housing density, costs, car parking options etc. (see Table 1 ) which vary across individuals $n$ according to the applied experimental design. In the CLM, the predicted probability of observing outcome $m$ is given by

$$
\operatorname{Pr}\left(y_{n}=m \mid X_{n}\right)=\frac{\exp \left(V_{n m}\right)}{\sum_{j e J} \exp \left(V_{n j}\right)}=\frac{\exp \left(X_{n m} \beta\right)}{\sum_{j e J} \exp \left(X_{n j} \beta\right)} \quad \text { for } m=1 \text { to } J
$$

$\operatorname{Pr}\left(y_{n}\right)$ is the probability of individual $n$ choosing alternative $m$ and $V_{n m}$ is the systematic (measurable) utility, which is a function of $X_{n m}$ and the vector $\beta . X_{n m}$ defines a matrix of attributes which pertain to choice options and $\beta$ contains the parameters indicating the effects of the independent attributes of choosing one alternative over another. In most applications, $V_{n m}$ takes a linear-in-parameters additive form.

In this study, we identify segments of private homebuyers with taste differences according to concepts of sustainable housing and additional attitudinal data: individual-specific characteristics regarding socio-economic background, perceptions and attitudes can help to explain choice behavior and preference beyond the concept of pure rational choice. Consequently, we collected additional data on respondent and household socio-economic characteristics (e.g., age, education, wealth status), as well as information to measure the environmental awareness of the respondents. Four selected items in the form of a rating scale were included to the questionnaire and an index on "environmental awareness" was composed (see Table 3 ) in order to measure the respondents" attitudes towards the environment [24] [32]. We did so to measure the effects of bounded rationality in a sense that "environmental awareness" is a concept "binding" rational choice of respondents.

The attributes of the index "environmental awareness" were integrated into a

Table 3. Variables for the generation of index "environmental awareness".

\begin{tabular}{|c|c|}
\hline Index: & Attributes added to the index \\
\hline "Environmental awareness" & 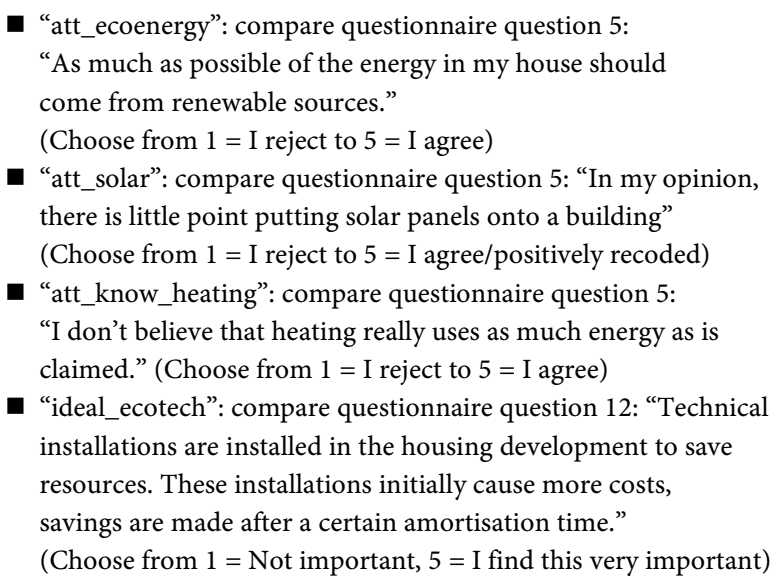 \\
\hline
\end{tabular}


factor analysis.In result, a one-principal component solution was arrived. As only one principal component was extracted, the four variables of the index seem to correctly reflect the intention of an indicator of the respondents" "environmental awareness" (the MSA of the factor analysis was 0.699; the extracted principal component explains $50.62 \%$ of the total variance; Cronbachs Alpha $=0.67)$.

\section{Results}

\subsection{Results of Discrete Choice Analysis and Segmentation by "Environmental Awareness" of Respondents}

To analyse heterogeneity of tastes of stated preferences of respondents, we used the index of "environmental awareness" (see above), i.e. we used the factor analysis results and the main components coefficient values, respectively, as co-variate in the latent class model analysis. To do so, we used the Latent Gold Choice 4.0 software. We specified calculations for a two- , three- and four class model (see Table 4).

The number of segments that has the closest fit to the "real number of market segments" in the sample cannot be defined by estimating latent segment models. Instead, statistics such as LL, $\mathrm{R}^{2}$, BIC, AIC or AIC3 have to be used to evaluate the fit of the models. The lower the statistics, the better the fit of the model. Looking at the 4-class model statistics, the AIC only improves very little over the 3-class model, while the AIC3 and the BIC increase considerably. Hence, the 4-class model was excluded from further analysis. However, the 3-class model shows only some minor improvement with respect to AIC and AIC3 over the 2-class model. Further analysis of the coefficient values of the 2-class and 3-class models revealed that the 3-class model could be interpreted as to show preferences of respondents of low environmental awareness in one class and preferences of respondents of high environmental awareness in the two other classes. Likewise, the 2-class model results could be interpreted as to show preferences of respondents of low environmental awareness in one class and preferences of respondents of high environmental awareness in the other class. Consequently, for ease of interpretation, the 2-class segmentation model was chosen to describe choice set results for respondents of different "environmental awareness".

Besides the coefficient values for the model attributes, the $\mathrm{p}$-values for $\mathrm{t}$-comp and additional Wald test statistics were calculated. Significant statistics showed that most attributes differed significantly between the two segments. Also, turning to discuss the coefficient values of the covariate "environmental awareness",

Table 4. Statistics for different models calculated with latent gold choice 4.0 software.

\begin{tabular}{ccccccc}
\hline & $\mathrm{LL}$ & $\mathrm{BIC}(\mathrm{LL})$ & $\mathrm{AIC}(\mathrm{LL})$ & $\mathrm{L}^{2}$ & $\mathrm{R}^{2}(0)$ & $\mathrm{R}^{2}$ \\
\hline 2-Klassen-Modell & -1036.29 & 2240.49 & 2128.59 & 2039.32 & 0.37 & 0.35 \\
3-Klassen-Modell & -1003.70 & 2265.25 & 2093.40 & 1974.13 & 0.47 & 0.44 \\
4-Klassen-Modell & -987.69 & 2323.18 & 2091.39 & 1942.12 & 0.54 & 0.52 \\
\hline
\end{tabular}


the sample is significantly divided up into one segment of "high environmental awareness" (coeff. eco $0.26^{\star}$ ) and one segment of "low environmental awareness" (coeff. noeco- $0.26^{\star * *}$ ) with a significant $\mathrm{t}$-comp value $(-3.51)$. Table 5 gives the results for the overall model as well as for the segmentation model.

Results for the "overall model"

First, we calculated a model for all respondents (“overall model”, see Table 5).

Table 5. Results of latent class models $(\mathrm{n}=402)$.

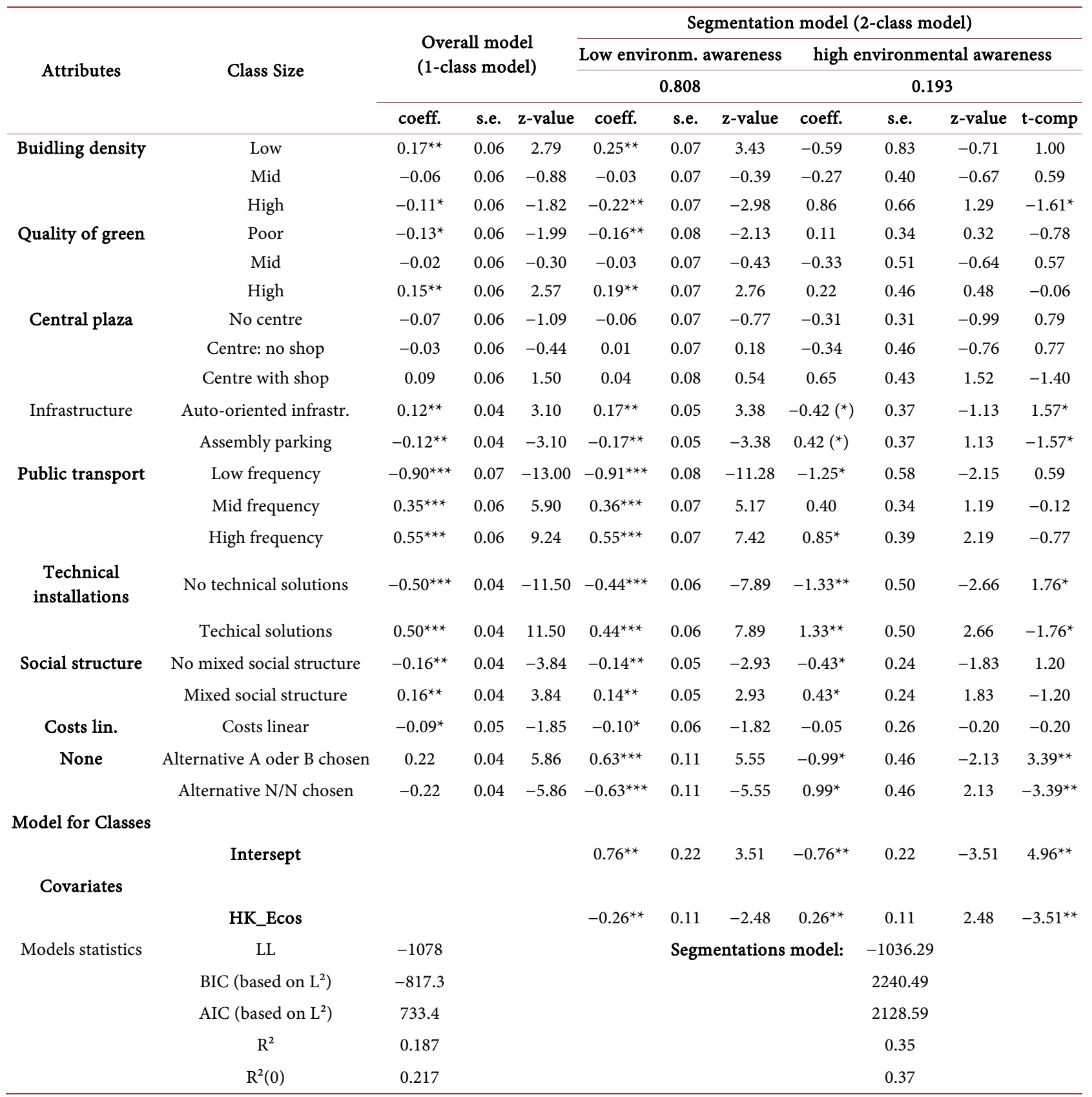

${ }^{1}$ level of statistical significance (two-tailed tests): ${ }^{* *} p<0.001$; ${ }^{* *} p<0.01 ;{ }^{*} p<0.05$; " $p<0.1$. ${ }^{2}$ The attributes are coded in effects coding (except for the cost attribute, which is linear coded). Effects coding means that the attributes will sum to zero over the categories of the nominal attribute concerned. For two level variables, here, only one level is shown, as the other is the negative equivalent (except for the infrastructure provision attribute, where coeff.-values for both levels are shown for explanatory reasons). Latent GOLD Choice 4.0 computes the required design vectors using effects coding (ANOVA type) for nominal dependent variables. 
The model adequacy was measured using Pseudo- $\mathrm{R}^{2}(0)$, which reached a value of 0.22 and documents a good model fit [33]. In the models, a positive coefficient value indicates that the attribute level has a positive effect of choosing one alternative over another, whilst a negative coefficient value displays a negative effect. Almost all of the housing development attributes are significant and have the expected sign. For example, the probability of a housing development being preferred increases as costs decrease. The "central plaza" attribute is the only attribute in the one-class model analysis without statistical significance, suggesting that this variable does not make a difference to the respondents" choice of housing development options in the one-class model.

Beginning with the density parameter, three levels of density were provided for analysis. The positive value for the low building density parameter (represented by single family houses in the empirical model; see Table 2) shows that this was preferred by the respondents over the two levels of higher building densities (represented by row houses and apartments in the empirical model). This means that the more row houses and apartments and the less one-family homes there are in a housing development model, the less likely respondents are to choose it. This result is consistent with other studies [22] [34], where results showed that people preferred lower building densities to higher building densities. A large number of green spaces have a positive impact on the probability of a housing development being chosen. To the extent that any style of housing development can provide large green areas (represented by approximately one small tree and one large tree per site and two streets additionally lined with trees; see Table 2), people would prefer to live in such "green" neighbourhoods. Morrow-Jones et al. (2004) conducted a conjoint analysis using the common MNL analysis method and found out that in general and all else being equal, the presence of any kind of green spaces (parks or agricultural land) positively affects the likelihood of a housing profile being chosen [22].

The "infrastructure provision" attribute showed a positive parameter value for the auto-oriented infrastructure development, represented by streets for cars throughout the neighbourhood and car parking provided directly in front of each building. An alternative transport infrastructure development was conceptualized in the empirical model as a variant with cluster or assembly parking and connected walkways to the houses. However, the negative value for the assembly parking variant and the positive value for the auto-oriented infrastructure indicate that the preferred option was the conventional auto-oriented infrastructure development.

The highest coefficient values in the one-class model were recorded with respect to the "public transport" attribute: "Medium" as well as "good local transport connections" were both rated positively by the respondents, suggesting that the marginal value of local transit services increases as the frequency of transit services increases. The high approval of "public transport" could be a consequence of the fact that many households in Germany are not only reliant on individual means of transport but also on additional public transport: in Germany, 
around two thirds of all households that rely on public transport also have one household member who uses a car on a typical working day [35].

With regard to the use of technical installations to improve energy efficiency, such as solar panels on the roofs of buildings, the respondents evaluated the installation of solar panels positively. A housing development with solar panels is more likely to be chosen than a conventional housing development that does not make use of photovoltaic or solar thermal systems. This could be attributed to the current state subsidies attached to solar thermal and photovoltaic panels in Germany and the resulting market dynamics [36].

Socially mixed housing development alternatives were preferred to homogeneous resident social structures, concerning income and age. In general and all else being equal, respondents would like to live in socially diverse neighbourhoods rather than in communities with residents of equal age and income.

The value of the cost attribute indicates that the effect on utility of choosing a housing alternative with a higher building cost level is negative. This corresponds to economic theory [26] [37]. The cost attribute, like all other attributes in the statistical design of the choice experiment, was assigned to each alternative by means of orthogonal coding. Cost levels have not been specifically attributed to any other independent variable, and no willingness-to-pay measures are reported in this paper. The negative value and statistical significance of the cost attribute, however, indicate that the respondents perceived it as an effective measure of cost constraints.

Finally, the "none" attribute was specified to equal 1 when either housing development option $\mathrm{A}$ or $\mathrm{B}$ was selected in a choice set, and to equal 0 when the "neither housing development A nor B" option was selected. The positive and significant value of the "none" parameter implies that the respondents preferred to choose one of the two housing development options A or B in the choice sets over the "neither A nor B" option. In other words, the respondents showed interest in comparing both and choosing one of the two housing development options and the housing development characteristics rather than generally opting for neither of them. The results of the one-class model analysis show that more conservative development planning, corresponding to the status quo of housing developments in Germany, is favoured by the target group of private home buyers.

\section{Results for the segmentation model}

Turning to discuss the segmentation model, results show a different pattern of preferences for sustainable housing and transport development among respondents of "high" or "low environmental awareness", respectively (Table 5).

Analysing the preferences within the two segments, we found almost all attributes to have at least one level showing the statistical significance in the group of respondents with "low environmental awareness", while there were less parameters significant among respondents of "high environmental awareness". The differences in respondents choices can be attributed to class memberships as follows: in a similar way to the one-class model results, respondents with "low 
environmental awareness" preferred single family homes over row houses and apartment houses. In contrast, however, the "eco" segment would prefer to live in higher building densities. This finding indicates a high potential for significant resource savings: for example, higher building densities with row and apartment houses instead of single-family homes or duplex/semi-detached houses would reduce the present amount of land consumption for new housing developments in Germany by approximately 50\% [13].

The segment of the "environmentally aware" did not express statistically significant approval or disapproval with regard to green spaces. However, the "non-environmentalist" segment of respondents (segment one) significantly disapproved of a poor quality of green spaces" within the development site. Both the "non-eco" and "eco" segments showed no statistical significance for levels of the "central plaza" attribute.

The parameter estimates for the "infrastructure provision" attribute illustrate some contrary opinions among the segments according to different parameter values: respondents with "low environmental awareness" chose the auto-oriented option over the pedestrian-oriented infrastructure development. In contrast, the segment of respondents of high "environmental awareness" would prefer assembly parking and pedestrian-oriented development over auto-oriented development. This finding is in contrast to some literature, where "pedestrian-oriented" infrastructure is said to be difficult to implement, as residents would not want to live in a neighbourhood that does not provide on-site parking facilities [38]. In this study, however, we found that a segment of respondents prefer pedestrian over auto-oriented development, which might be attributed to noise reduction and improved quality of life in pedestrian-oriented neighbourhoods.

With regard to "public transportation services," "technical installations for resource protection" and "representation of social classes," all respondents shared relatively similar preferences, as the parameters show the same signs among all two segments: the "environmentally aware," however, rated a high frequency of public transport much higher than the "non-environmentally aware." This is in line with other research: Zhang concludes that more pedestrian-oriented urban design (which was preferred by the "eco" segment of respondents in this study) makes transit services more likely to be considered by travellers [39].

To sum up, the results of the latent class analysis can be interpreted in line with the assumed preferences of people with "high environmental awareness" and people with "low environ-mental awareness" with regard to content. The group of respondents with "high environmental awareness" approved of all attributes relating to sustainability as defined in this study, such as "higher densities" and "pedestrian-oriented" infrastructure. In contrast, respondents in the "non-environmentally aware" segment preferred more conventionally designed housing developments, especially with regard to lower building densities and auto-oriented infrastructure. 


\subsection{Developing a Decision Support System (DSS) from the Results of Discrete Choice Analysis}

The results of utility expressions given in Table 5 above can be used to be embedded in a decisions support system (DSS) and to calculate the impact of changes in levels of one or more attributes on the overall percentage of respondents choosing one alternative over the other [40]. In other words, the DSS shows potential "market shares" for the total sample or sub-samples thereof, such as respondents of "low" or "high environmental awareness". Consequently, composing a DSS from stated preferences data helps to interpret and discuss the results in more detail. The DSS consists of a frontend, where users are allowed to "interact with the program by changing the attribute levels of the underlying model" [40]. The models results or coefficient values, respectively, form the backend of the system and provide the information basis for the user interface in the frontend (Figure 1).

In this section, we provide results from the DSS, where different scenarios of "Option B" are calculated against the status quo of housing development provided in "Option A" of the DSS choice set (Table 6): (1) first, we show the DSS results with "Option $\mathrm{B}$ " specified to higher building densities as opposed to the status quo characterised by low building densities and single-family homes. (2) Second, we turn to discuss the effect of transport infrastructure development on potential market shares for housing developments where "Option B" was specified to contain of assembly parking and associated walkways to the buildings. (3) Third, we add another aspect of integrated urban and transport planning policies to the model by specifying "Option B" with additional high frequency of

\begin{tabular}{|c|c|c|c|}
\hline \multirow[b]{3}{*}{$\begin{array}{r}\text { density } \\
\text { quality of green } \\
\text { centre } \\
\text { development }\end{array}$} & \multicolumn{3}{|c|}{ Decision Support System } \\
\hline & Housing Option A & Housing Option B & Neither Option \\
\hline & $\begin{array}{c}\text { low } \\
\text { low } \\
\text { no centre } \\
\text { motor vehicle }\end{array}$ & $\begin{array}{c}\text { high } \\
\text { low } \\
\text { no centre } \\
\text { assembly parking }\end{array}$ & \\
\hline \multirow[t]{2}{*}{$\begin{array}{l}\text { public transport } \\
\text { technical solutions } \\
\text { social structure }\end{array}$} & $\begin{array}{l}\text { low frequency } \\
\text { no } \\
\text { not mixed }\end{array}$ & $\begin{array}{l}\text { high frequency } \\
\text { no } \\
\text { not mixed }\end{array}$ & \\
\hline & \multicolumn{2}{|c|}{ A cost the same than $B$} & \\
\hline \multirow{2}{*}{$\begin{array}{l}\text { Respondents with high environmental awareness (Class- } \\
\text { Size }=20 \% \text { ): } \\
\text { Respondents with low environmental awareness (Class- } \\
\text { Size }=80 \% \text { ): }\end{array}$} & $4,98 \%$ & $27,94 \%$ & $67,08 \%$ \\
\hline & $37,37 \%$ & $29,43 \%$ & $33,20 \%$ \\
\hline Total market share (preferences): & $30,89 \%$ & $29,13 \%$ & $39,98 \%$ \\
\hline
\end{tabular}

Figure 1. DSS frontend, developed using MS Excel software. 
Table 6. DSS results for different scenarios.

\begin{tabular}{|c|c|c|c|c|c|c|c|c|c|c|}
\hline Attributes: & $\begin{array}{c}\text { "Status Quo" } \\
\text { (specified as Option A } \\
\text { in the DSS choice set) }\end{array}$ & \multicolumn{3}{|c|}{$\begin{array}{l}\text { Scenario 1: } \\
\text { "Higher Density" }\end{array}$} & \multicolumn{3}{|c|}{$\begin{array}{l}\text { Scenario 2: } \\
\text { gher Density and as- } \\
\text { sembly parking" }\end{array}$} & \multicolumn{3}{|c|}{$\begin{array}{l}\text { Scenario 3: "Higher } \\
\text { density, assembly parking } \\
\text { and high frequency of } \\
\text { public transport" }\end{array}$} \\
\hline Density & Low density & \multicolumn{3}{|c|}{ High density } & \multicolumn{3}{|c|}{ High density } & \multicolumn{3}{|c|}{ High density } \\
\hline Quality of green & Low quality of green & \multicolumn{3}{|c|}{ Low quality of green } & \multicolumn{3}{|c|}{ Low quality of green } & \multicolumn{3}{|c|}{ Low quality of green } \\
\hline Centre & No centre & \multicolumn{3}{|c|}{ no centre } & \multicolumn{3}{|c|}{ No centre } & \multicolumn{3}{|c|}{ No centre } \\
\hline Development & Auto-oriented develop m. & \multicolumn{3}{|c|}{ Auto-oriented develop m. } & \multicolumn{3}{|c|}{ Assembly parking } & \multicolumn{3}{|c|}{ Assembly parking } \\
\hline Public transport & Low frequency & \multicolumn{3}{|c|}{ Low frequency } & \multicolumn{3}{|c|}{ Low frequency } & \multicolumn{3}{|c|}{ High frequency } \\
\hline Technical solutions & No & \multicolumn{3}{|c|}{ No } & \multicolumn{3}{|c|}{ No } & \multicolumn{3}{|c|}{ No } \\
\hline Social structure & Not mixed & \multicolumn{3}{|c|}{ Not mixed } & \multicolumn{3}{|c|}{ Not mixed } & \multicolumn{3}{|c|}{ Not mixed } \\
\hline Costs & $\begin{array}{l}\text { Option A costs the } \\
\text { same than Option B }\end{array}$ & \multicolumn{3}{|c|}{$\begin{array}{l}\text { Option A costs the } \\
\text { same than Option B }\end{array}$} & \multicolumn{3}{|c|}{$\begin{array}{l}\text { Option A costs the } \\
\text { same than Option B }\end{array}$} & \multicolumn{3}{|c|}{$\begin{array}{l}\text { Option A costs the same } \\
\text { than Option B }\end{array}$} \\
\hline & ket Share: & SQ & Sc. 1 & N/N & SQ & Sc. 2 & $\mathrm{~N} / \mathrm{N}$ & SQ & Sc. 3 & $\mathrm{~N} / \mathrm{N}$ \\
\hline "Respondents with & h environmental awareness": & $0.5 \%$ & $2 \%$ & $97 \%$ & $0.5 \%$ & $5 \%$ & $95 \%$ & $5.0 \%$ & $28.0 \%$ & $67.1 \%$ \\
\hline "Respondents with & environmental awareness": & $26 \%$ & $16 \%$ & $57 \%$ & $27 \%$ & $12 \%$ & $60 \%$ & $37.4 \%$ & $29.4 \%$ & $33.2 \%$ \\
\hline & Total: & $21 \%$ & $14 \%$ & $65 \%$ & $22 \%$ & $11 \%$ & $67 \%$ & $30.9 \%$ & $29.1 \%$ & $39.9 \%$ \\
\hline
\end{tabular}

public transport against the status quo alternative in "Option A". To focus on the effects of the density-, transport infrastructure- and public transport-parameters, we hold the cost attribute constant across all scenarios.

Scenario 1 has higher building densities as opposed to the status quo, which is disapproved of across all segments. While almost no respondent with "high environmental awareness" would like to live in a status quo-form of housing development in Germany, there is only little potential to improve the market share of more densely built housing ceteris paribus and all other attributes held constant according to the status quo option. In result, respondents tend to opt-out of the two options presented in scenario 1 . Consequently, the market share for the "neither"-option is as high as $65 \%$ for the total sample and even higher for the group of people of "high environmental awareness". We conclude that higher building densities might only be desirable if accompanied by other design-parameters of sustainable housing (see Scenarios 2 and 3).

In Scenario 2, "Option B" does not only have higher building densities but also differs from the status quo in that it contains of "assembly parking" and walkways to the buildings instead of an auto-oriented development with streets for cars and car-parking in front of buildings. In result, this leads more respondents with "high environmental awareness" to approve of this scenario (5\% as opposed to only $2 \%$ in scenario 1 ). Contrarily, less respondents with "low environmental awareness" approved of Scenario 2 as opposed to scenario 1, as this group of respondents did express preferences for auto-oriented transport infrastructure. As can be seen from the results for the "neither"-option, however, still the majority of respondents across segments opted for the "neither"-option and 
against both generic options A and B. We conclude, that adding assembly parking to higher building densities as a sustainability alternative to the status quo does only slightly increase market-shares for sustainable housing development and only in the segment of respondents of "high environmental awareness". Therefore, other accompanying aspects are necessary to improve its market potential.

Turning to discuss Scenario 3, "high frequency of public transport" was added to "Option B" of the DSS choice set. Hence, Scenario 3 reflects a sustainability scenario, where building densities are higher as opposed to the status quo of housing development as well as assembly parking is provided along with a high frequency of public transport. Surprisingly, in this scenario, both the respondents of "high environmental awareness" as well as those with "low environmental awareness" approved of the more sustainable housing development alternative in "Option B" as opposed to the status quo. We conclude that combining urban design sustainability attributes such as higher building densities with transport planning sustainability attributes such as assembly parking AND a higher frequency of public transport leads respondents to approve of this specific scenario of sustainable housing development.

\section{Conclusions on Integrated Policies of Urban Design and Sustainable Transport Planning}

The paper reports on a stated preferences survey among house buyers in Germany, using a discrete choice approach, where parameters of sustainable urban design and sustainable transport are both integrated into one model. From the results and the market shares modelled for different scenarios by means of a DSS, we conclude that sustainable transport infrastructure planning and sustainable urban design planning are closely related concepts from the perspectives of homebuyers in Germany. This gives evidence for implementing more integrated policies that take into account both urban design and transport-related aspects of sustainable planning. In addition, our results give support to measures that address sustainable urban and transport planning on a more local level, i.e. the level of neighbourhood planning.

Turning to the issue of high land consumption for new housing development in Germany, our results show preferences for higher building densities only among the group of respondents with "high environmental awareness". Higher building densities, however, are a key factor to limit land consumption in the housing sector [13]. In our discrete choice approach, we combined urban design and transportation infrastructure parameters in an integrated land use and transportation model. Therefore, we are able to analyze combined effects of these parameters in one model and with the help of a DSS. Analyzing DSS results, we conclude that higher building densities can reach higher market shares, when accompanied by preferred levels of the two transport-related parameters. In other words, the results show, that different measures of sustainable transport planning are needed to also improve market shares for sustainable urban design: 
market shares for higher building densities are especially improved when high frequency of public transport is added to the model. This means, high quality of public transit services adds to the market share of sustainable urban design. Likewise, adding assembly parking and walkways to the buildings results in higher rates of acceptance or higher market share for this type of planning, especially when combined with providing high frequency of public transit services. Combining public transport services and measures such as assembly parking and car-free neighbourhoods can reduce car ownership [41]. It can be concluded that a cooperation of public transport service providers and local planning authorities can add to both sustainability objectives in the land use and transportation sector. In Germany, local authorities are both responsible for land use planning and zoning plans as well as contracting public transport service providers. Our results show how a combined approach for zoning, transport infrastructure provision and provision of public transport services can be used to implement effective local land use policies and hence add to reach national and local sustainability objectives.

The stated choice study presented here is limited in that it did not take into account the context of the decision making process of private house buyers. Literature in the field of social psychology, for instance, argues that the context a decision is embedded in is an important factor influencing actual choice [42]. Further research, therefore, is necessary to investigate the impact of framing or other context-related effects on house-buying decisions.

\section{References}

[1] Thierstein, A. (2017) Introduction-Chair of Regionale Development. http://www.re.ar.tum.de/startseite/

[2] German Federal Agency for the Environment (UBA) (2014) Greenhouse Gas $/ \mathrm{CO}_{2}$ Emissions in Germany.

http://www.umweltbundesamt.de/daten/klimawandel/treibhausgas-emissionen-indeutschland\#textpart-1

[3] German Federal Statistical Office (2016) Monitoring Land Consumption in Germany.

https://www.destatis.de/DE/ZahlenFakten/Wirtschaftsbereiche/LandForstwirtschaft Fischerei/Flaechennutzung/Aktuell.html

[4] Hassenpflug, D., Ed. (2000) Die Europäische Stadt-Mythos und Wirklichkeit. Münster.

[5] Bayern Labo, Ed. (2014) Wohnungsmarkt Bayern 2005-Beobachtung und Ausblick. München.

[6] Federal Government of Germany (2016) German Strategy for Sustainable Development.

https://www.bundesregierung.de/Content/DE/StatischeSeiten/Breg/Nachhaltigkeit/ 0-Buehne/2016-05-31-download-nachhaltigkeitsstrategie-entwurf.pdf?_blob=publi cationFile\&

[7] Hartl, J. and Lee, E.-H. (2003) Ökosiedlungen. Seoul, Berlin.

[8] World Commission on Environment Development (1987) Our Common Future. Oxford University Press, Oxford. 
[9] German Federal Environment Agency, Ed. (2000) Szenarien und Potentiale einer nachhaltig flächensparenden und landschaftsschonenden Siedlungsentwicklung. Berlin.

[10] Williams, K. and Dair, C. (2007) What Is Stopping Sustainable Building in England? Barriers Experienced by Stakeholders in Delivering Sustainable Developments. Sustainable Development, 15, 135-147. https://doi.org/10.1002/sd.308

[11] Wolpensinger, H. and Rid, W. (2010) Environmentally Sustainable Housing: Standards and Innovation. Detail, 3, 122-128.

[12] German Federal Statistical Office (2015) Housing Development in Germany. https://de.statista.com/statistik/daten/studie/253690/umfrage/baugenehmigungen-i m-wohnbau-nach-bauherr-in-deutschland/

[13] Sieverts, T. (2005) Zwischenstadt. Wuppertal.

[14] Gigerenzer, G. and Selten, R. (2001) Bounded Rationality. The Adaptive Toolbox. The MIT Press, Cambridge, Massachusetts and London, England.

[15] Simon, H. (2000) Bounded Rationality in Social Sciences: Today and Tomorrow. Mind \& Society, 1, 25-39. https://doi.org/10.1007/BF02512227

[16] Becker, G. (1982) Der ökonomische Ansatz zur Erklärung menschlichen Verhaltens. Tübingen, Mohr.

[17] Friedrichs, J. and Opp, K.-D. (2002) Rational Behaviour in Everyday Situations. European Sociological Review, 18, 401-415. https://doi.org/10.1093/esr/18.4.401

[18] Simon, H. (1955) A Behavioral Model of Rational Choice. The Quarterly Journal of Economics, 69, 99-118. https://doi.org/10.2307/1884852

[19] Tversky, A. and Kahneman, D. (1974) Judgement under Uncertainty: Heuristics and Biases. Science, 185, 1124-1131.

[20] Tversky, A. and Kahneman, D. (1981) The Framing of Decisions and the Psychology of Choice. Science, 211, 453-458.

https://doi.org/10.1126/science.7455683

[21] Avineri, E. and Prashker, J. (2006) The Impact of Travel Time Information on Travelers' Learning under Uncertainty. Transportation, 33, 393-408.

https://doi.org/10.1007/s11116-005-5710-y

[22] Morrow-Jones, H.A., Irwin, E.G. and Roe, B. (2004) Consumer Preference for Neotraditional Neighborhood Characteristics. Housing Policy Debate, 15, 171-202. https://doi.org/10.1080/10511482.2004.9521498

[23] Louviere, J. and Woodworth, G. (1983) Design and Analysis of Simulated Consumer Choice or Allocation Experiments: An Approach Based on Aggregate Data. Journal of Marketing Research, 20, 350-366. https://doi.org/10.2307/3151440

[24] Louviere, J., Hensher, D.A. and Swait, J.D. (2000) Stated Choice Methods-Analysis and Application. University Press, Cambridge, UK. https://doi.org/10.1017/CBO9780511753831

[25] Birol, E., Karousakis, K. and Koundouri, P. (2006) Using a Choice Experiment to Account for Preference Heterogeneity in Wetland Attributes: The Case of Cheimaditida Wetland in Greece. Ecological Economics, 60, 145-156.

[26] Boxall, P.C. and Adamowicz, W.L. (2002) Understanding Heterogenious Preferences in Random Utility Models: A Latent Class Approach. Environmental and Resource Economics, 23, 421-446. https://doi.org/10.1023/A:1021351721619

[27] Grêt-Regamey, A., Bishop, I. and Bepi, P. (2007) Predicting the Scenic Beauty Value of Mapped Landscape Changes in a Mountainous Region through the Use of GIS. Environment and Planning B, 34, 50-67. https://doi.org/10.1068/b32051 
[28] LBS (Bundesgeschäftsstelle Landesbausparkassen), Ed. (2004) Eigentumsbildung im Wohnungsbau. Schriftenreihe LBS Marktforschung 26, Berlin.

[29] Dutton, W.H., Helsper, E.J. and Gerber, M.M. (2009) The Internet in Britain. Oxford.

[30] Vogt, K. (1999) Verzerrungen in Elektronischen Befragungen? Online Research, Göttingen.

[31] Morey, E., Thacher, J. and Breffle, W. (2006) Using Angler Characteristics and Attitudinal Data to Identify Environmental Preference Classes: A Latent-Class Model. Environmental and Resource Economics, 34, 91-115. https://doi.org/10.1007/s10640-005-3794-7

[32] Schahn, J., Damian, M., Schurig, U. and Füchsle, C. (1999) Konstruktion und Evaluation der dritten Version des Skalensystems zur Erfassung des Umweltbewußtseins (SEU-3.) (Bericht aus dem Psychologischen Institut der Universität Heidelberg, Diskussionspapier Nr. 84, März 1999).

[33] Constanzo, C.M., Halperlin, W.C., Gale, N.D. and Richardson, G.D. (1982) An Alternative Method for Assessing Goodness-of-Fit for Logit Models. Environment and Planning A, 14, 963-971. https://doi.org/10.1068/a140963

[34] Gordon, P. and Richardson, H. (1997) Are Compact Cities a Desirable Planning Goal? Journal of the American Planning Association, 63, 95-106. https://doi.org/10.1080/01944369708975727

[35] Franz, R. (2006) Nachhaltigkeitsmilieus in den Bedürfnisfeldern Ernährung, Wohnen und Mobilität. Consumer Science, 6.

[36] Asendorpf, D. (2006) Mehr Watt von oben. Die Zeit, 26, 27-28.

[37] Bergmann, A., Hanley, N. and Wright, R. (2006) Valuing the Attributes of Renewable Energy Investments. Energy Policy, 34, 1004-1014.

[38] Fuchs, O. and Schleifnecker, T. (2001) Handbuch ökologische Siedlungsentwicklung. Initiativen zum Umweltschutz, 32, Berlin.

[39] Zhang, L., Herzog, T. and Hauser, G. (2006) Transparent Thermal Insulating MultiLayer Membrane Structure for Building Envelope. International Conference on Adaptable Building Structures, Eindhoven (NL).

[40] Hensher, D.A., Rose, J.M. and Green, W.H. (2005) Applied Choice Analysis: A Primer. Cambridge University Press, Cambridge. https://doi.org/10.1017/CBO9780511610356

[41] Celsor, C. and Millard-Ball, A. (2007) Where Does Carsharing Work? Using Geographic Information Systems to Assess Market Potential. Transportation Research Record: Journal of the Transportation Research Board, 1992, 61-69. https://doi.org/10.3141/1992-08

[42] Gigerenzer, G. (2010) Moral Satisficing: Rethinking Moral Behavior as Bounded Rationality. Topics in Cognitive Science, 2, 528-554.

https://doi.org/10.1111/j.1756-8765.2010.01094.x 
Submit or recommend next manuscript to SCIRP and we will provide best service for you:

Accepting pre-submission inquiries through Email, Facebook, LinkedIn, Twitter, etc. A wide selection of journals (inclusive of 9 subjects, more than 200 journals)

Providing 24-hour high-quality service

User-friendly online submission system

Fair and swift peer-review system

Efficient typesetting and proofreading procedure

Display of the result of downloads and visits, as well as the number of cited articles Maximum dissemination of your research work

Submit your manuscript at: http://papersubmission.scirp.org/

Or contact tel@scirp.org 